\title{
The importance of collaborative design process and fabrication during COVID-19 emergency - case in Brazil
}

\author{
Regiane Trevisan Pupo \\ UFSC | Brasil | regipupo@gmail.com \\ Luiz Salomão Ribas Gomez \\ UFSC | Brasil | salodesigner@gmail.com
}

\begin{abstract}
The current pandemic situation, in which Brazil and the world are going through, has had devastating effects, as well as actions of adaptation, adequacy and solidarity among the world population. The latest ways of automated form materialization using digital fabrication equipment, aided by the creativity of students, teachers, and researchers, have collaborated in the creation of several artifacts around COVID-19. This article reports an experience, right at the beginning of the pandemic in Brazil, of a collaboration design process in the creation and production of an emergency equipment, from the idea to its distribution to society, in record time, preserving quality and efficiency of the proposed product.
\end{abstract}

Keywords: Face Shields; FabLab; COVID-19.

\section{INTRODUÇÃO}

A pandemia de COVID-19, que desde meados do mês de março deste ano ameaça o Brasil e o mundo, tem modificado formas de relacionamentos, aprendizado e trabalho em todas as camadas da sociedade. Sistemas colaborativos online e virtuais tem surgido em diversos segmentos e colaborado para a obtenção de material e suprimentos de proteção contra o vírus da COVID-19.

Segundo a orientação provisória (OPAS/BRA/Covid-19/20041) de 06 de abril de 2020, da Organização Mundial de Saúde (OMS) em conjunto com a Organização PanAmericana da saúde (OPAS), "as gotículas respiratórias são geradas quando uma pessoa infectada tosse ou espirra" (OMS, 2020). Assim, a orientação alerta ainda que "qualquer pessoa que estiver em contato próximo (distância de um metro) com alguém com sintomas respiratórios (tosse ou espirros) corre o risco de ser exposta" (OMS, 2020).

Mais recentemente, a orientação sobre o uso de máscaras no contexto da COVID-19, deliberado pela OMS, em junho de 2020, ressalta que os equipamentos de proteção individual do tipo FaceShield podem ser considerados uma alternativa. Este tipo de equipamento, que são protetores individuais presos à cabeça e com frente protetora em material totalmente transparente, funciona como uma primeira barreira de proteção contra a possível contaminação por partículas suspensas no ar ou secreções advindas de outras pessoas.

O uso de FaceShields se torna imprescindível quando utilizado junto com outros tipos de proteção facial, visto que as máscaras de pano não são apropriadas para uso médico ou para pessoas em atendimento de saúde.
Entretanto, a orientação da OMS ainda ressalta que o design deste tipo de equipamento seja assegurado em cobrir ambos os lados do rosto, bem como abaixo do queixo, com a maior e segurança e conforto possíveis.

Visando a produção imediata destes equipamentos de segurança, muitas iniciativas começaram a surgir com o eminente perigo de contaminação. Laboratórios considerados como Espaços Maker, ou laboratórios de fabricação digital, podem ter um papel importante na produção destes equipamentos de proteção, além de respiradores e outros sistemas de proteção, devido a acessibilidade de equipamentos que possibilitam a fabricação em pequenas quantidades de artefatos customizados e de qualidade.

Richard Florida (2014) afirma que um Centro de Inovação ou Parque Tecnológico deve estar tão próximo da Universidade para que essa distância seja percorrida de bicicleta (não por um atleta). Porém, esse limite físico precisa ser diminuído e, como apresenta Gary Stager (2013), em seu discurso, um "FabLab" deve estar na mochila do estudante. Entende-se por "FabLab" um laboratório de fabricação digital equipado com máquinas de fabrico digital (Troxler et al, 2010). O conceito de FabLab é ainda recente e teve origem no Massachussets Institute of Technology (MIT), nos Estados Unidos, em 2002, por meio de um curso intitulado "Como fazer (quase) qualquer coisa", ministrado pelo professor Neil Gershenfeld. Por princípio, os "FabLabs" constituem espaços abertos à comunidade. Sendo assim, a Universidade, espaço onde os "FabLabs" estão se instalando prioritariamente no mundo todo, descobriram que precisam mudar seu papel nessa nova economia criativa e de compartilhamento, onde os "prossumidores" (que produzem e consomem), estão construindo um Novo 
Poder Social e de uso das novas tecnologias para melhor atender suas necessidades.

O PRONTO3D - Laboratório de Prototipagem e Novas Tecnologias Orientadas ao 3D, do curso de Design da Universidade Federal de Santa Catarina (UFSC), em Florianópolis, Brasil, foi criado em 2013 e vem, ao longo destes sete anos, investindo no ensino, na pesquisa e na extensão, com atuação em diversos cursos da universidade e comunidade em geral. A disseminação da tecnologia e sua utilização em processos distintos de projeto resumem o diferencial do laboratório que prima pela diversificação de aplicações, o que o levou à certificação como "FabLab" MIT, em 2016. Com infraestrutura composta pelas tecnologias de Fabricação digital (aditivas, subtrativas e formativas), o laboratório promove workshops, oficinas e treinamento para uma diversidade de público, inclusive crianças, no intuito de promover a tecnologia como simples ferramenta, em que a criação e a inovação caminham num mesmo patamar.

Quando em 2012 um workshop construído pela FAPESC Fundação de Amparo à Pesquisa de Santa Catarina (que viria ser a financiadora da rede PRONTO3D) e a ELISAVA da Espanha para apresentação de tecnologias de fabricação digital acontece no Sapiens Parque em Florianópolis, não se imaginava que pudesse surgir dali uma rede estruturada de "FabLabs" espalhada por todo o estado de Santa Catarina. Atualmente com quatro unidades instaladas em diferentes cidades de Santa Catarina, a rede PRONTO3D recebe centenas de estudantes e membros da comunidade todos os anos. $\mathrm{O}$ PRONTO3D de Florianópolis foi apenas um dos laboratórios da rede a se envolver intensamente na produção de FaceShields durante a pandemia. O mesmo acontecendo em Criciúma e Chapecó.

A cada semestre, o laboratório de Florianópolis recebe bolsistas, estagiários e monitores, que compõem uma equipe comprometida e participativa em todas as atividades contidas e promovidas pelo laboratório. Este excessivo investimento em treinamento pôde ser concretizado na experiência aqui relatada, mostrando sua eficácia, fora dos muros da universidade, na qual os estudantes puderam perceber a importância da capacitação, no trabalho de excelência e na colaboração servindo à sociedade.

Desde sua implementação, as atividades inerentes ao laboratório sempre foram de forma presencial. Não havia, até o momento, nenhuma prática projetual com atividades remotas, tampouco experiências com ferramentas que possibilitassem estas ações. Algumas tentativas de projeto colaborativo com o apoio da fabricação digital tiveram sucesso, mas com alguns procedimentos presenciais e locais nas dependências do laboratório, no campus da universidade.

Frente à pandemia do COVID-19, que abalou e ainda abala o mundo, o trabalho aqui apresentado caracteriza o trajeto de produção de um equipamento de emergência, desde a ideia até a sua distribuição para a sociedade, em tempo recorde, sem suprimir da qualidade e eficiência do produto proposto. Ainda, o desafio foi o de coordenar espaços remotos de produção para a excelência do produto. A discussão culmina com os limites, possibilidades e realidades da impressão 3D se comparados a produções de grande escala.

\section{DA IDEIA AO DESENVOLVIMENTO}

Foi durante a terceira semana no mês de março de 2020, no início da crise pandêmica no Brasil, que o laboratório PRONTO3D de Florianópolis iniciou uma empreitada na elaboração, produção e distribuição de FaceShields frente às notícias de alastramento do corona vírus no Brasil. Em ação importante e necessária num momento crítico no qual a universidade mostra seu papel, as iniciativas da equipe utilizaram não só a estrutura física do laboratório, mas de alunos, professores e voluntários, que possuíam impressoras 3D em casa e que poderiam ajudar nas impressões dos FaceShields, remotamente.

A ideia e viabilidade do projeto com a elaboração de máscaras protetoras tipo FaceShields veio de uma demanda da Prefeitura Municipal de Florianópolis, tendo como público alvo, além da sociedade em geral que pudesse utilizar o produto, os garis e motoristas municipais que transportam profissionais de saúde nas frentes de trabalho. Estes profissionais estão constantemente expostos a situações de risco e necessitam de máxima proteção para desenvolver suas atividades corriqueiras.

A situação era de extrema urgência e foi a partir daí que se iniciou a busca de voluntários (alunos, professores, pesquisadores e profissionais da área de Design), para que se pudesse montar uma equipe de projeto e impressão $3 \mathrm{D}$ dos produtos requeridos, em tempo recorde e de forma remota. Antes, porém, foi necessário estabelecer uma equipe que pudesse 1) pesquisar acerca dos produtos semelhantes existentes atualmente no mercado e 2) definir um projeto que estivesse ao alcance da realidade local e condições de fabricação em tempo mínimo possível com os equipamentos disponíveis nos pontos remotos. Dois alunos do curso de Design de Produto da UFSC, Gabriela Chicarelli e Arthur Baltazar, confinados em suas residências e com equipamentos pessoais de impressão 3D disponíveis, executaram as duas etapas e seguiram para os testes de materialização. Em pouco tempo e, após diversas tentativas de acerto e erro, como é comum em processos projetuais baseados na materialização da forma, obtiveram um produto que atendia às premissas estabelecidas.

O projeto contou também com a ajuda do professor Affonso Orciuoli, que mora em Barcelona, Espanha, que gentilmente colaborou, remotamente, nas variáveis para o fechamento dos arquivos para impressão e otimização de tempo de fabricação. O artefato é composto por um suporte de cabeça produzido em impressão 3D, do tipo FDM (Fused Deposition Modeler), no qual uma lâmina de PETG (Tereftalato de polietileno modificado), cortada a laser, é fixada em pontos específicos do suporte, para a total proteção do usuário (Figura 1). Hoje, este tipo de proteção já se tornou comum em diversas frentes de combate ao vírus, comércio, e qualquer atividade que tenha contato com o público em geral. 

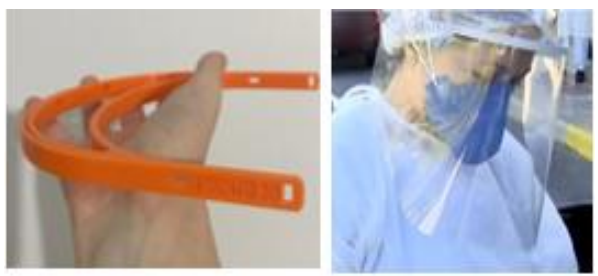

Figura 1: Produto Criado para o projeto

Com o projeto definido, era necessário, naquele momento, a sua validação por um profissional de saúde, para que o produto pudesse ser utilizado por uma gama extensa da sociedade com segurança. Foi então que o professor e pesquisador do Departamento de Microbiologia, Imunologia e Parasitologia da UFSC, Dr. Oscar BrunãRomeiro, testou e validou o produto. Indicou algumas pequenas modificações que deveriam ser seguidas para a total segurança em sua utilização e manuseio e a validação foi emitida por vídeo, produzido em sua própria residência, onde 0 professor se encontrava em quarentena.

Concomitantemente, o contato com possíveis voluntários para a fabricação ia sendo efetuado e o compromisso firmado. A partir disso, foi possível distribuir os arquivos aos voluntários para dar início às impressões em 3D, montando assim um hub remoto de produção, com 12 pontos, em diferentes locais da região de Florianópolis. Como cada voluntário possuía equipamentos distintos, foi necessário dar atenção pontual a cada um, para que as configurações fossem estabelecidas e todos os modelos tivessem a mesma saída impressa. Tudo era alinhado e controlado, remotamente, pela coordenadora do projeto, autora deste artigo.

Acompanhando o tempo de produção de impressão 3D, um hub de corte laser foi montado para o corte das lâminas de PETG, que fazem parte do conjunto dos FaceShields. Este, contou com duas empresas locais e que possuem parceria com o PRONTO3D, a AUTOMATISA LASER e a DUE LASER. As configurações do corte também foram desenvolvidas pelos alunos e repassadas às empresas. É importante salientar que os materiais para a produção das FaceShields, ou seja, filamento para impressão 3D e PTEG, foram doados, respectivamente, pela APUFSC SINDICAL (Sindicato dos Professores das Universidades Federais de Santa Catarina) e pelo CoCriationLab (Laboratório de Pré-incubação da UFSC).

\section{TRABALHO COLABORATIVO}

A nova economia mundial está saindo das mãos de poucos e ficando disponível para todos, não no formato antigo de capitalismo e/ou socialismo, mas numa nova vertente de "Economia Colaborativa" (RIFIKIN, 2016). Nela, o poder das patentes e da capacidade de produzir sai das grandes corporações e fica disponível cada vez mais para o cidadão comum. O conceito do DIY (do it yourself), por exemplo, está mais presente e a Universidade precisa entender isso se posicionando para preparar melhor seus alunos para essa nova realidade (CHRISTENSEN, 2014).

Sabendo disso e querendo aproveitar da oportunidade de construir um novo modelo de Universidade a pergunta que surgiu foi: Como realizar o trabalho colaborativo, uma das premissas fundamentais de um Espaço Maker, em pleno momento de distanciamento social e lockdown?

Era preciso realizar as atividades de desenvolvimento, programação, testes e avaliação em ambientes físicos e distantes, por vezes de milhares de quilômetros, já que em nossa equipe, conforme já citado, tinham membros no Brasil e na Europa. A melhor maneira de construir essa rede colaborativa foi utilizando de ferramentas digitais e contemporâneas para integração dos membros e validação dos resultados.

Foram criados grupos em comunicadores digitais e de emails, além do uso de sistemas de vídeo conferência para visualização dos resultados. Também foram usados aplicativos de transporte com Uber para agilizar na movimentação de amostras pois a segurança dos envolvidos era fundamental até para que a cadeia não se quebrasse e evitar que o resultado fosse prejudicado na obtenção do sucesso desejado.

Foram envolvidos participantes do laboratório PRONTO3D, do COCriation Lab, técnicos da prefeitura, professores, pesquisadores e empresas parceiras para formar a rede colaborativa de criação, desenvolvimento e produção das FaceShields. Com a professora Regiane Pupo à frente da gestão do grupo colaborativo (inclusive ela em região diferente da maioria dos participantes) se construiu um canal de comunicação dinâmico com respostas rápidas, o que tornou a colaboração mais efetiva e o resultado plenamente adequado às necessidades.

Além do trabalho colaborativo para a produção das Face Shields, foi realizado um trabalho de apoio com a participação da rede FERA-SC (Fundo Empresarial para Reação Articulada de Santa Catarina Contra o Coronavírus) da Federação da Indústrias de Santa Catarina (FIESC), onde o Professor Luiz Salomão Ribas Gomez contribuiu na gestão do desenvolvimento de moldes para a injeção em ABS de suportes para máscaras para serem produzidas em larga escala, etapa posterior à descrita neste artigo.

Esta ação entre o laboratório e a indústria fortalece ainda mais o conceito colaborativo que se faz presente permanentemente na Rede PRONTO3D. Tem-se claro o limite da fabricação digital e fabricação industrial e, quando os moldes para a injeção das FaceShields começaram a ser produzidos, concluiu-se que a missão do grupo havia terminado e todos se colocaram à disposição da indústria para testes e distribuição dos FaceShields, encerrando, assim, a produção em impressão 3D que, naquele momento, já era muito lenta e cara para a necessidade atual.

\section{O CRONOGRAMA DE ATIVIDADES}

Como o tempo entre o design e a fabricação dos equipamentos era muito reduzido, um cronograma de atividades, detalhado na Tabela 1, foi montado e ilustra as ações desenvolvidas pela equipe de voluntários para que o objetivo tivesse êxito, dentro do tempo estabelecido.

Neste cronograma, que sofreu poucas alterações no decorrer da realização das atividades, foram levadas em conta diversas situações e contingências, tais como a 
logística de busca das impressões 3D e cortes a laser, a montagem do material, quebra de equipamentos, além da situação de possível lockdown que poderia influenciar em toda a cadeia produtiva. Para isso foram criados grupos de comunicação digital em app adequado, onde as equipes puderam em real time organizar todas as atividades.

Tabela 1: Cronograma das Atividades

\begin{tabular}{l}
\hline Semana 1 \\
\hline Ideia e viabilidade do projeto de proteção contra o COVID19; \\
Busca e seleção dos voluntários; \\
Equipe de Design para proposta do produto de proteção; \\
Pesquisa de projetos de FaceShields Open Source no \\
mercado; \\
. Definição de projeto. \\
\\
\hline Semana 2 \\
Montagem de hub de impressão voluntário; \\
Montagem de hub de corte laser voluntário; \\
Procura de doação de material para impressão 3D (PLA); \\
cristal); \\
Montagem de equipe de logística; \\
Ajustes no projeto.
\end{tabular}

\section{A EQUIPE}

Os doze pontos que compunham o hub de impressão foram distribuídos em 1) seis alunos de graduação (Design de produto, Engenharia Mecânica e Produção), 2) três professores e 3) três profissionais independentes. Como as partes que compunham as FaceShields estavam sendo produzidas em locais distintos, a montagem final delas foi de responsabilidade da Prefeitura Municipal de Florianópolis, para onde os produtos eram levados após cada retirada. As retiradas eram programadas e efetuadas a cada dois dias, em cada local do hub, por uma equipe coordenada pela Prefeitura Municipal de Florianópolis. A partir daí, podiam ser distribuídas aos usuários e funcionários.

O envolvimento de todos no projeto foi conduzido de forma cautelosa, profissional e coerente, num momento em que se iniciava uma situação nunca vivenciada. 0 país e 0 mundo passavam por situações de atenção, evidenciando uma incerteza e medo, mas que, ao mesmo tempo, o pensamento de solidariedade e ânsia por ajudar ao próximo estavam inerentes. Alguns dos colaboradores puderam dar seus depoimentos acerca de suas experiências no trabalho aqui montado e podem ser acompanhadas acessando o QR-Code na figura 2.

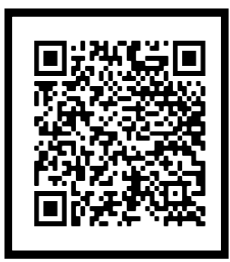

Figura 2: Acesso aos depoimentos dos envolvidos

A produtividade de cada envolvido na produção variou entre os equipamentos de cada um, distintos em marca, tamanho, disponibilidade de produção e otimização do seu próprio tempo. Não houve por parte da coordenação dos hubs de impressão nenhuma imposição quanto ao número de peças produzidas, tampouco tempos mínimos para as entregas. Mesmo assim, a produção foi intensa e maior que a esperada.

\section{O "DRIVE THRU” DA SAÚDE}

Florianópolis foi uma das primeiras cidades do Brasil a decretar o distanciamento social e aplicar a quarentena no comércio, indústria e escolas. Já no dia 16 de março foi publicado o decreto municipal 21340/2020 que dispunha sobre as medidas para enfrentamento da emergência de saúde pública em importância internacional decorrente da infecção humana pelo novo CORONAVÍRUS (COVID-19) e dá outras providências, já aplicando normas pesadas par controle da disseminação do vírus.

A cidade foi a primeira também a propor testes em massa na população com aquisição de 13.000 testes rápidos de COVID-19 que foram aplicados emergencialmente na população para identificar precocemente o contágio e assim mitigar a transmissão do vírus afastando os infectados do convívio social o mais breve possível.

O "Drive Thru" da saúde foi a iniciativa da Prefeitura Municipal de Florianópolis encontrada para aplicação dos testes rápidos. Consiste em um conjunto de ações de medição de temperatura e testes da Covid-19, em que cidadãos, previamente agendados e com suspeita de estarem contaminados, eram testados, em seus próprios veículos, por profissionais de saúde que atuam em um dos terminais de ônibus da cidade, desativado durante a pandemia.

A sequência de imagens da figura 3 ilustra estes profissionais em ação, com as FaceShields produzidas como resultado deste projeto. 

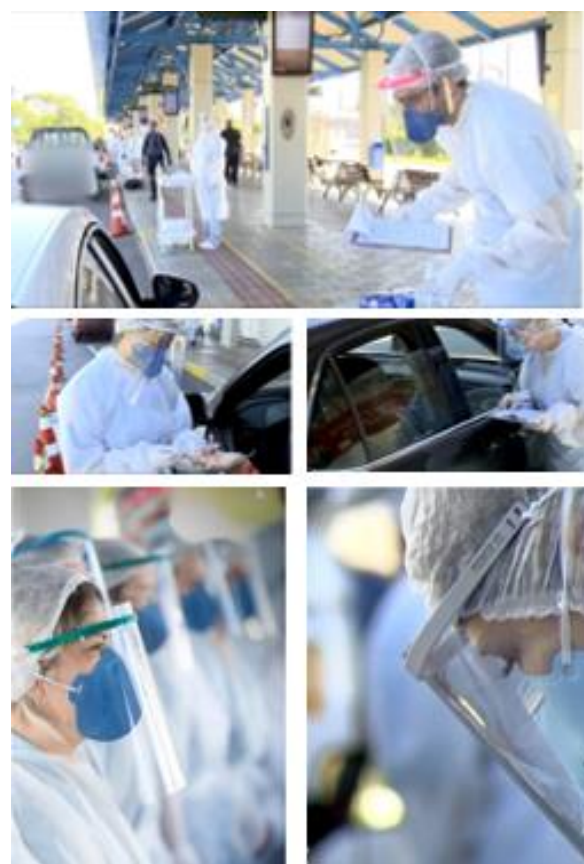

Figura 3: Ações do "Drive Thru" da saúde
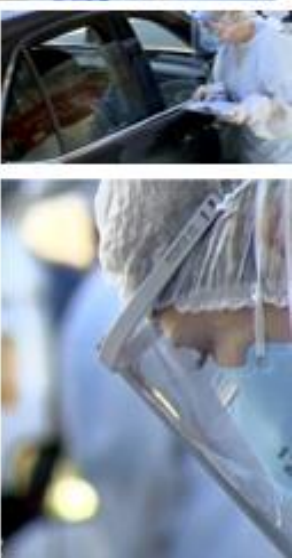

\section{CONSIDERAÇOES FINAIS}

É sabido que a tecnologia de impressão 3D se mostra útil quando sua produção não ultrapassa maiores quantidades. A demanda no momento da pandemia exige que estas quantidades sejam de milhares de unidades fabricadas, rapidamente. Com isso, a produção em impressão 3D, por mais que se obtenham voluntários espalhados pelo Brasil e insumos sendo doados por empresas e pessoas dispostas a colaborar, ainda não será suficiente para atender a quem mais precisa. Assim, em parceria com a indústria, houve uma mobilização das empresas na fabricação dos suportes injetados, chegando a uma produção de mais de 15000 unidades por dia.

Entender a função de um FabLab na sociedade é fundamental para que ele atue em prol das necessidades apresentadas e, em seu devido tempo, possa estabelecer parcerias mais amplas com a indústria. Além disso, é fundamental saber usar o conhecimento produzido para proporcionar mais eficiência aos movimentos, muitas vezes lentos, das grandes empresas. O histórico do PRONTO3D demonstra que tem aplicado essa função no cotidiano do laboratório e a ação das FaceShields só reforça a assertividade de metodologia empregada.

Com a rotina de seis semanas intensas de produção e distribuição, foi possível fabricar um pouco mais de 600 unidades (Figura 4) que foram distribuídas para o público alvo previamente estabelecido, além da distribuição aos profissionais de saúde que trabalhavam no inédito "Drive Thru da saúde", em parceria com a Prefeitura Municipal de Florianópolis.
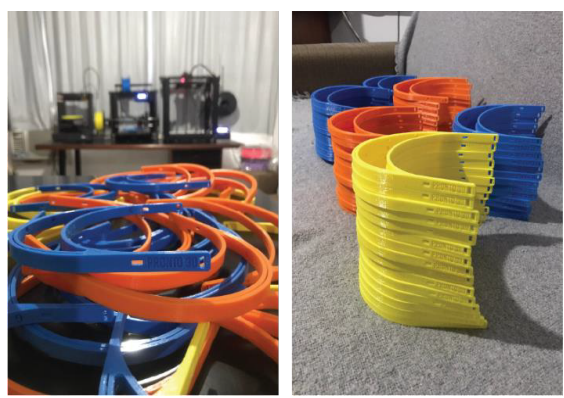

Figura 4: Suportes impressos

Uma reportagem da ND Mais TV, afiliada da Rede Record, foi veiculada sobre a ação do PRONTO3D durante a pandemia de COVID-19 na mídia local, em 26 de março de 2020 e mostra as ações na busca imediata de soluções no combate ao corona vírus para os profissionais que bravamente estão à frente desta luta. A reportagem, intitulada "Universitários de unem para produzir máscaras em impressão3D" pode ser acessada pelo QR-Code da figura 5 ou no link do YouTube: https://www.youtube.com/watch?v=02tUX_IzyCl\#action= share.

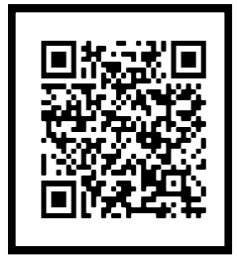

Figura 5: Reportagem NDMais TV

\section{AGRADECIMENTOS}

Os autores agradecem à UFSC (Universidade Federal de Santa Catarina), FAPESC (Fundação de Amparo à Pesquisa de Santa Catarina), FIESC (Federação das Indústrias de Santa Catarina), Automatisa Laser Solutions, DUE Laser, APUFSC (Associação dos Professores da UFSC), CocreationLab e aos voluntários de impressão 3D, sem os quais este projeto não teria sido realizado.

\section{REFERÊNCIAS}

All 3DPrinting Retrieved from https://all3dp.com/1/coronaviruscovid-19-sars-cov-2-3d-printing/

Christensen, C. \& Eyring, J. (2014). A Universidade Inovadora: Mudando o DNA do Ensino Superior de Fora pra Dentro. São Paulo, SP: Bookman.

COPPER 3D. Retrieved from https://copper3d.com/ Retrieved from $22 / 03 / 2020$

DUNN, N. (2010). Architectural Model Making. London: Laurence King Publishing. ISBN: 9778-185669-670-8.

FLORIDA, R. (2012). The rise of the creative class: and how it's transforming work, leisure, community and everyday life. New York, NY: Basic Books.

LIOU, F. (2008). Rapid Prototyping and engineering applications: a tool box for prototype development. London: CRC Press. ISBN: 978-0-8493-3409-2 
LIPSON, H.; KURMAN, M. (2013). Fabricated: The new world of 3D Printing. Indianapolis: John Willey \& Sons.

Porque não imprimir em 3D dispositivos médicos em casa - um apelo. Retrieved from https://www.linkedin.com/pulse/porquen\%C3\%A3o-imprimir-em-3d-dispositivos-m\%C3\%A9dicoscasa-daniel-huamani

RIFKIN, J. ( 2016). Sociedade com custo marginal zero. Makron books: São Paulo.

THOMPSON, R. (2011). The manufacturing guides prototyping and low-volume production. London: Thames\&Hudson. ISBN 978-0-500-28918-1.
TROXLER, P. \& SCHWEIKERT, S. (2010). "Developing a business model for concurrent enterprising at the Fab Lab", pp. 1-8.

WHO/2019-nCov/IPC_Masks/2020.3. Retrieved from https://apps.who.int/iris/handle/10665/331693

WHO/2019-nCov/IPC_Masks/2020.4 Retrieved https://apps.who.int/iris/handle/10665/331693 